radiation records, but by giving equal weight to all observations he found that $a$ has a range from 0.08 to 0.19 ; and $b$ varies from 0.63 to 0.95 . Neither constant shows any systematic geographical variation. Having got local values of $a$ and $b$ from short-period records, he applied them to large neighbouring araas with long-term records of $n$, to derive expected mean monthly average values of $Q$. These were plotted together with the corresponding values given by Black $^{3}$ for twenty-eight stations in the area bounded by lat. $50-60^{\circ} \mathrm{N}$., long. $5-30^{\circ} \mathrm{E}$., and isopleths of mean monthly radiation drawn for north-west Europe using the two sets of estimates. The value of the twelve maps lies in their detail, and this may be modified after a re-check of some of the basic data. When published, they will be a very useful supplement to the corresponding maps of rainfall, temperature and sunshine.

During recent years there has grown a demand for more information about the effects of shelter on plants and on animals. Much of the resulting field work has the active co-operation of the Meteorological Office in Edinburgh, and in a paper entitled "Windbreaks - Some Physical Effects", Dr. R. W. Gloyne of that Office considered some purely aerodynamic aspects of air flow over a barrier. Summarizing world experience, he listed the three distinct flow regions that arise : (1) the up-wind boundary layer ; (2) the down-wind disturbed region; and (3), overlying these, the undisturbed flow. The disturbed region can be subdivided into: $(2 a)$ a space, immediately behind the obstacle where there may be strong eddies-it is here where it is most difficult to reconcile field and wind-tunnel studies; $(2 b)$ a region, farther down-wind, of turbulent motion, approximately conforming to a logarithmic profile, which, with distance, becomes in fact the logarithmic profile of the original undisturbed flow. The sizes of the regions (as multiples of the barrier height $h$ ) vary with the permeability $(\varphi)$ of the barrier. In brief (with winds of normal incidence) : for dense barriers $(\varphi<40$ per cent) the original profile is re-established at about 30\%, though a logarithmic profile may re-appear at $20 h$, and the original mean direction is re-established at about $15 h$. For open barriers ( $\varphi>60$ par cənt) the re-establishment of speed profiles is much as for dense barriers, but that of mean direction occurs much nearer the barrier, perhaps as olose as $2 \frac{1}{2} h$ behind a very open mesh. The width of the affected area depends on the length $(L)$ of the barrier. When $L>20 \%$, the system behaves almost as a portion of an infinite barrier; a shorter barrier has relatively larger edge effects so that the affected area varies roughly as $L^{2}$, approximating to a parabola with its vertex perhaps $1 \frac{1}{2} L$ down-wind.

Dr. Gloyne concluded with a brief reminder that there is a pressure excess up-wind and a pressure deficiency down-wind of an obstacle placed in an air stream, and he suggested that pressure measuraments, similar to those made in wind tunnels, might be useful in wind-break studies.

H. L. Penman

${ }^{1}$ Penman, H. L., and Long, I. F., Quart. J. Roy. Met. Soc., 86, 16 (1960) ${ }^{2}$ Monteith, J. L., and Szeicz, G., Quart. J. Roy. Met. Soc., 86, 205 (1960) ${ }^{3}$ Black, J. N., Archiv. für Met., Geophys, und Biokl., B10, 2 (1960).

\title{
TUBERCULOSIS IN ANIMALS
}

$\mathrm{T}$ UBERCULOSIS in animals was the subject of the fourth symposium of the Zoological Society of London, held on May 24. Mr. J. N. Ritchie, who organized the meeting, presided at the evening session. Dr. R. E. Glover was chairman at the morning session, and in the afternoon Dr. J. M. Ross filled this position.

Dr. Glover explained that the subject was appropriate for discussion at this particular time because of the progress that had been made in the eradication of tuberculosis from the cattle in Great Britain. With this advance, it was useful to review the position among other animals.

The first paper was by Dr. J. T. Stamp, who dealt with the comparative pathology. In calves, the incidence of tuberculosis is low, and infection enters mainly by inhalation or is congenital. Hæmatogenous dissemination is frequent. The fact that the incidence of tuberculosis increases considerably with age shows conclusively that tuberculosis of the adult is not merely a slow progression of lesions acquired in calfhood. In the older animals, the site of the primary complex is predominantly pulmonary and it is very obvious that advanced pulmonary tuberculosis develops as a result of bronchial dissemination following cavitation of the primary lung focus. The pathology of tuberculosis of the udder shows that there is always extensive involvement of the milk ducts.

In the pig, the chief route of infection is by the alimentary tract, and this gives rise to an incomplete primary complex in the regional lymph glands. In bovine-type infection in this species, hæmatogenous dissemination is common, but chronic pulmonary tuberculosis occurs only infrequently.

Horses have a high resistance to tuberculosis. Primary infection is almost entirely by ingestion. Hæmatogenous dissemination is frequent and gives rise either to miliary tuberculosis or to large tumourlike swellings, not unlike those of sarcoma.

The tuberculin test and the laboratory diagnosis of tuberculosis were discussed by I. W. Lesslie, who gave a brief history of the methods of preparation of tuberculin and the ways in which it had been used.

The general objective of research on tuberculin is to obtain a preparation which will give a maximum response in the infected animal at all stages of sensitization and a minimum response in the noninfected or non-specifically sensitized animal. $\mathrm{He}$ described the procedure necessary for the characterization of tuberculins.

The intradermal comparative tuberculin test has been developed for use in cattle. It consists in the injection of $0.1 \mathrm{ml}$. of avian and mammalian tuberculins in selected sites in the neck. The reaction at each site is measured, and the test is interpreted on each animal with reference to the results recorded in the whole herd and having regard to the herd history and clinical findings. P.P.D. tubereulin is used (mammalian $2.5 \mathrm{mgm}$./ml., avian $0.5 \mathrm{mgm}$./ml.) The relative strength of the P.P.D. tubereulins resulted from somewhat empirical decisions based on the strength of the tuberculins formerly used in this test. 
A laboratory service is of great value in confirming field diagnosis and, particularly, for typing the organisms concerned. Frequently, when re-infection in a herd of cattle is being investigated, the knowledge of the type of organism involved is helpful in tracing the source of infection, both in animals and in man.

Mr. J. D. Blaxland, in describing tuberculosis in poultry, said that it is no longer of great importance as a cause of serious loss in our flocks. This relates generally to the lower age of birds being kept and the better conditions of husbandry. Nevertheless, tuberculosis still accounts for a fairly high proportion of condemnations of poultry carcases. The disease affects domestic and wild birds. There is no good evidence that wild birds play any large part in infecting domestic species, but apparently wild birds do acquire infection from poultry. Wild birds may, however, be responsible for infecting farm animals.

Organisms of the avian type may cause progressive disease in pigs, and account for about one-third of the reports of tuberculosis in British pigs. Avian-type infection in cattle is important because it sensitizes the animal to tuberculin and, unless some form of comparative tuberculin test is used, may lead to errors in diagnosis.

Mr. I. M. Lauder, discussing tuberculosis in dogs and cats, mentioned that the incidence is much reduced. Bovine-type infection is now rare among cats, but a few cases of human-type infection occur. Tuberculosis was found in 1-2 per cent of autopsies of dogs in veterinary schools in Great Britain in the last five years. Infection in dogs is mainly of humantype and a source in man has been found in 77 per cent of cases, usually within the household. Symp. toms in dogs are readily recognizable, and in these animals diagnosis may be made by $\mathrm{X}$-ray examination. The tuberculin test is not reliable but a test using B.C.G. vaccine intradermally is of some value. Many of the comparatively few cases of tuberculosis found in dogs are 'open' and humans might therefore be infected from this source.

In a paper on the disease in zoo animals, Mr. Oliver Graham-Jones emphasized that the primates are very susceptible, and it is common in all vertebrate species. All three main types of the organism are involved. Many carnivores, which might be expected to acquire bovine tuberculosis from eating infected meat, instead are found to be infected with a human strain apparently from close contact with the general public.

Bovine infection has been recorded in monkeys, although one would expect the infection to be with the human strain entirely.

There is considerable difficulty in diagnosis because the usual signs of loss of condition leading to emaciation are not so apparent in animals in captivity. The use of laboratory techniques in diagnosis is becoming more important; but it is recognized that a suitable diagnostic test is needed. The only test available at present is the intradermal tuberculin test, as developed for cattle. There is some promise, however, from the use of B.C.G. vaccine which was developed by the author as a diagnostic aid in primates and has since been used in dogs.

Treatment is, of course, possible; but it was stressed that eradication of the disease by destruction of the affected animal, and prevention of recurrence by strict measures of disinfection was the best practical course. Precautions have, of course, to be taken by testing incoming animals with tuberculin. So far as possible, this should be done before the animals leave their country of origin; but this is sometimes quite impracticable. Whatever the practical difficulties of carrying out tuberculin tests and eradicating the disease from zoo animals, it was most important to appreciate that in the light of the current successful eradication programme for tuberculosis in cattle, it is most undesirable that zoological gardens should remain a reservoir of infection which might overspill into rural areas.

Mr. R. V. Blamire, dealing with tuberculosis and food inspection, pointed out that although tuberculosis has, in the past, been regarded by food inspectors as the most important animal disease, its significance has rapidly declined in recent years in Great Britain. More than 97 per cent of milk consumed is now either heat-treated or comes from attested herds.

The techniques of meat inspection are exacting, and the judgment of tuberculous carcases is often difficult.

In 1957 , approximately $7 \cdot 3$ per cent cattle, $0 \cdot 1$ per cent calves, 3.6 per cent pigs, and 0.0006 per cent sheep were found to be affected with tuberculosis when inspected in abattoirs in England and Wales. In 1950, it is estimated that the value of meat rejected because of tuberculosis was about $£ 1,000,000$; in 1955, although the price of meat had doubled, $£ 800,000$, and in 1957 it was $£ 500,000$. Soon, the loss should be negligible.

The risk to public health from the consumption of under-cooked tuberculous meat has never been clearly established; but it should not be under-estimated. The detection of tuberculosis by meat inspectors will in future have more animal health than public health significance. Differential diagnosis will then become very important.

The disease in man was dealt with by Prof. J. W. Crofton.

With the greater control of malaria, tuberculosis has become the world's most important public health problem. The World Health Organization calculates that $0.5-1$ per cent of the entire population of the world is coughing up tubercle bacilli at any one time. Since the introduction of modern chemotherapy in 1947, there has been a dramatic fall in mortality from tuberculosis, at least in the economically developed countries; but the fall in notifications has been very much slower. Human infection by bovine tubercle bacilli can be measured directly only by typing bacilli isolated from patients. Indirect estimates can be made by following trends of tuberculosis in young children, who are likely to be infected from milk, or of such forms as abdominal tuberculosis which are likely also to be associated with milk infection. Figures quoted demonstrated such falls, greater in urban areas, where milk infection was first well controlled, than in rural areas, and much greater than the falls in respiratory tuberculosis.

The control of infection with human bacilli depends on efficient case-finding, mainly by mass miniature radiography, on efficient treatment to render patients permanently non-infectious, on efficient prophylactic vaccination with B.C.G. and on the general improvement in environmental conditions. Figures for Edinburgh were quoted to show the dramatic effect relatively thorough re-organization and good teamwork can have not only on the mortality but also on the morbidity of tuberculosis. It is suggested that, with sufficient energy and enthusiasm, the elimination of tuberculosis could be proceeding much more rapidly than it is in most areas at the present time. 
Mr. W. D. Macrae traced the story of the eradication of tuberculosis from cattle from its beginning with the introduction of the Tuberculosis Attested Herds Schemes in 1935 . It proved relatively easy to reduce an incidence of 20 per cent to 0.3 per cent ; but there is real difficulty in reducing this figure any further for various reasons, such as re-infection from other animal sources, including man; loss of tuberculin reactivity at certain stages of the disease; and residual infection on farms, particularly in old, dilapidated buildings.

The overall current incidence of infection is $0 \cdot 16$ per cent of the animals tested but in some areas it is now as low as 0.05 per cent. Whether it will ever be reduced beyond this figure is a matter for conjecture.

Among the reactors disclosed, some 70 per cent show evidence of disease at postmortem examination in abattoirs. This figure of confirmation was higher at one stage but has fallen somewhat as a result of difficulties in carrying out adequate postmortem examinations and the apparent increase in the number of reactors showing no visible lesions.

In the course of dealing with bovine tuberculosis, the incidence in pigs of the bovine type infection has been markedly reduced and may well disappear in this species.

A great deal of effort is still required to maintain the disease under strict control. There must be regular organized tuberculin testing at appropriate intervals and tracing of animals which have been in contact with infection, so that the herds to which they have moved may be tested. Every source of information of the presence of tuberculosis in cattle must be used, including abattoirs and knackeries.

Tuberculosis in cattle, although not eradicated in a literal sense, is at least under satisfactory control, and there is every promise that it will be maintained at an extremely low incidence in future. Coincidentally, the amount of infection among other animals has been reduced in parallel, but certain precautions are still necessary to prevent re-infection of herds of cattle. Man may remain a source of infection, and while bovine-type tuberculosis in man is probably not sufficiently common among people who are in close contact with animals to make this a serious hazard, it has to be appreciated that as the interval between tests of herds is extended any source of re-infection is very important.

\section{THE BRITISH GELATINE AND GLUE RESEARCH ASSOCIATION}

\begin{abstract}
THE nineteenth meeting of the Research Panel of the British Gelatine and Glue Research Association was held on May 19, with the chairman of the Association, Mr. S. G. Hudson (Richard Hodgson and Sons, Ltd.), in the chair.

Dr. G. R. Tristram (Department of Physiology and Biochemistry, University of St. Andrews) presented "A Preliminary Study of the Thermal Conversion of Acid-soluble Calf-skin Collagen into Gelatin". The collagen was obtained by extraction of calf-skin with cold aqueous acetic acid. The release of endgroups on heating with water at $p H \mathbf{H}$ was investigated, using Sanger's method. Changes in optical rotation and viscosity caused by heating at $p \mathrm{H} \quad 3 \cdot 3$ in $0.1 M$ aqueous acetic acid solution were recorded. At $p \mathrm{H} 6$, most of the collagen dissolved after $\mathrm{I} \mathrm{hr}$. at $50^{\circ} \mathrm{C}$. and all of it after $1 \mathrm{hr}$. at $60^{\circ} \mathrm{C}$. Solubilization was accompanied by a large increase in $\varepsilon$-amino groups reactive towards Sanger's reagent and by the appearance of terminal amino-groups of a similar pattern to those found in eucollagen by Courts ${ }^{1}$. End-groups were also estimated after keeping the collagen in strong aqueous urea at $15^{\circ} \mathrm{C}$. so as to obtain a comparison with the effect of heating in water. On heating at $p \mathbf{H} 3 \cdot 3$ the optical rotation and viscosity rose to a maximum at about $28^{\circ} \mathrm{C}$. and then fell. Dr. Tristram drew some tentative conclusions about the unmasking of $\mathrm{N}$-terminal residues during the treatments applied and discussed the question of there being one or more chains in the collagen structure.
\end{abstract}

The second paper, "The Swelling of Gelatine Films", by Miss E. M. Simms and Mr. J. N. Blake (Richard Hodgson and Sons, Ltd.), was presented by Mr. Blake. A variety of gelatine gels and sols were dried on a solid supporting base at various temperatures in the range $5-60^{\circ} \mathrm{C}$. The resultant thin films were detached and allowed to swell freely in water at $10^{\circ} \mathrm{C}$.; previous workers in this field have studied attached films. The weights and dimensions of the swollen films were measured. By far the most important factor controlling swelling was the temperature at which the films were dried; for example, a $210 \mathrm{~g}$. Bloom acid-process pigskin gelatine film, imbibed twenty-three times its weight of water if dried at $5-10^{\circ} \mathrm{C}$. but only six times if dried at $30-35^{\circ} \mathrm{C}$. The imbibition was largely evidenced by an increase in thickness rather than in linear dimensions, whereas films dried from the sol state exhibited the opposite behaviour. Swelling in water at $20^{\circ} \mathrm{C}$. was considerably greater than at $10^{\circ} \mathrm{C}$. and swelling was more pronounced in films dried from weak (5 per cent) solution than from strong ( 20 per cent) solution. Films dried unrestrained on liquid surfaces from both sols and gels exhibited subsequent swelling of the sol form type. The extensive results were discussed in terms of the molecular orientation of the systems during drying.

Mr. A. M. Kragh (British Gelatine and Glue Research Association) gave the final paper, entitled "The Flocculation of Suspensions with Gelatine". Gelatines and animal glues have a flocculating action on a wide variety of suspended solids of which quartz has been most studied, and this property has been evaluated in comparison with that of other flocculating agents both polyionic (for example, synthetic polyamides) and non-ionic (for example, dextran). Gelatine flocculates best where almost all of it is adsorbed on to the particle surfaces and where the amount so adsorbed is about one-third of the maximum adsorbable. It is exceptional among flocculating agents in its ability to be strongly adsorbed on a wide range of different surfaces and in that its flocculating action is strongly dependent on $p \mathrm{H}$. The lively discussion centred around the mechanism by which flocculation is induced in these systems.

${ }^{1}$ Courts, A., Biochem. J., 74, 238 (1960). 